Archives of Clinical and Medical Case Reports

doi: $10.26502 /$ acmcr.9655001

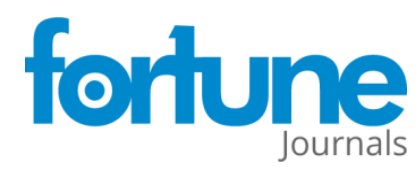

Volume 1, Issue 1

Case Report

\title{
Henoch-Schönlein Purpura in an Adult 53 years old
}

\author{
E. Pelechas ${ }^{1}$, A. Kavvadias ${ }^{2}$, N. Tsigaridas ${ }^{3}$, P. Karagianni ${ }^{4}$, P. Tsapogas ${ }^{5}$ \\ ${ }^{1}$ University Hospital of Ioannina, Rheumatology Department, Ioannina, Greece \\ ${ }^{2}$ University Hospital of Ioannina, Gastroenterology Department, Ioannina, Greece \\ ${ }^{3}$ Chatzikosta General Hospital, Cardiology Department, Ioannina, Greece \\ ${ }^{4}$ University Hospital of Ioannina, Laboratory Department, Ioannina, Greece \\ ${ }^{5}$ Henry Dunant Hospital, Internal Medicine Department, Athens, Greece
}

"Corresponding Author: Eleftherios Pelechas, University of Ioannina, Medical School, Stavrou Niarchou street, Ioannina, Greece, Mobile: +306979868855, Tel +302651099832; E-mail: pelechas@ doctors.org.uk

Received: 05 July 2017; Accepted: 10 July 2017; Published: 17 July 2017

\begin{abstract}
Henoch-Schönlein Purpura (HSP) is a systemic leukocytoclastic vasculitis often noted as a skin rash with skin lesions such as petechiae and palpable purpura. A 53-year-old man presented with a 5-day history of eruptions on his legs and right arm that were mildly pruritic. The lesions were palpable and had been preceded by 10 days of a mild upper respiratory tract infection. The patient did not have any arthralgias, haematochezia or abdominal pain but only a weight reduction during the last 4 months. The diagnosis of HSP has been confirmed by histologic evaluation that revealed leukocytoclastic vasculitis with IgA immune deposits on the vessel walls. Patients with skin rashes must be investigated thoroughly for the prevention of any secondary complications of the disease.
\end{abstract}

Keywords: Henoch-Schönlein; Leukocytoclastic Vasculitis; Purpura 


\section{Introduction}

Henoch-Schönlein Purpura (HSP) is a systemic leukocytoclastic vasculitis often noted as a skin rash with skin lesions such as petechiae and palpable purpura [1]. The rash of HSP usually is accompanied by arthralgias, abdominal pain, and renal disease. It may appear after a remote history of infection (often an upper respiratory tract infection) [2]. HSP affects children at a rate of 15 cases/100,000 individuals annually [3]. The disease occurs less frequently in adults, in whom the natural course of the disease is not as well understood and it can lead to renal impairment or other serious complications [4].

\section{Case Report}

A 53-year-old man with a personal medical history of arterial hypertension (treated with ACE inhibitors and $\mathrm{K}^{+}$ sparing antihypertensive), presented with a 5-day history of eruptions on his legs (Figure 1) and right arm that were mildly pruritic. The lesions were palpable and had been preceded by 10 days of a mild upper respiratory tract infection. The patient did not have any arthralgias, haematochezia or abdominal pain but only a weight reduction during the last 4 months, without any changes on his appetite. From the laboratory results, the patient had elevated IgA $(741 \mathrm{mg} / \mathrm{dl})$. C3, C4, ANA, ANCA, ds-DNA and RA test were negative. The rest of the laboratory results were of no significance. 24 hours urine collection, urine dip test, urea and creatinine did not show any kidney impairment of albuminuria. Upper gastrointestinal endoscopy revealed a peptic ulcer whereas lower gastrointestinal endoscopy revealed diverticulosis of the sigmoid and descending colon. Abdominal CT showed hepatomegaly, fatty infiltration of the liver and a focal calcification on the right lobe of the liver. The diagnosis has been confirmed by histologic evaluation that revealed leukocytoclastic vasculitis with IgA immune deposits on the vessel walls. The patient had been followed for any complications for a period of 6 months, but there was a spontaneous remission of the rash. He has been treated for the peptic ulcer with PPI's.

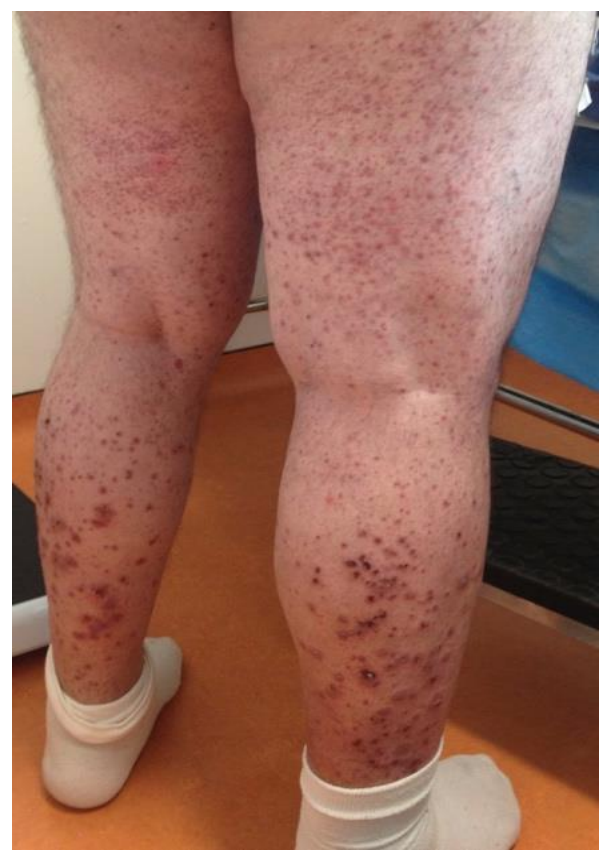

Figure 1: Palpable purpura in the lower extremities. 


\section{Discussion}

HSP predominantly affects children (younger than 5 years) [5]. The tetrad of rash, arthralgia, abdominal pain and renal disease can occur in any order over any time period, and all 4 symptoms do not have to be present clinically [6]. Gastrointestinal tract lesions [7] and renal involvement [8] is common in patients with HSP. Patients with skin rashes must be investigated thoroughly for the prevention of any secondary complications of the disease.

\section{References}

1. Meadow SR, Scott DG. Berger disease: Henoch-Schönlein syndrome without a rash. J Pediatr 106 (1985): 2732.

2. Cameron JS. Henoch-Schönlein purpura: clinical presentation. Contrib Nephrol 40 (1984): 246-249.

3. Saulsbury FT. Henoch-Schönlein purpura in children. Report of 100 patients and review of the literature. Medicine 78 (1999): 395-409.

4. Nielsen HE. Epidemiology of Schönlein-Henoch purpura. Acta Paediatr Scand 77 (1988): 125-131.

5. Blanco R, Martinez-Taboada VM, Rodriguez-Valverde V. Henoch-Schönlein purpura in adulthood and childhood: two different expressions of the same syndrome. Arthritis Rheum 40 (1997): 859-864.

6. Pillebout E, Thervet E, Hill G. Henoch-Schönlein purpura in adults: outcome and prognostic factors. J Am Soc Nephrol 13 (2002): 1271-1278.

7. Yoshikawa N, Yamamura F, Akita Y. Gastrointestinal lesions in an adult patient with Henoch-Schönlein purpura. Hepatogastroenterology 46 (1999): 2823-2824.

8. Garcia-Porrua C, Gonzalez-Louzao C, Llorca J. Predictive factors for renal sequelae in adults with HenochSchönlein purpura. J Rheumatol 28 (2001): 1019-1024.

This article is an open access article distributed under the terms and conditions of the

Creative Commons Attribution (CC-BY) license 4.0 